\title{
Exploring Arab Media Group's Motivations for Using Facebook
}

\author{
Abdul-Karim Ziani, Bahrain University \\ Mokhtar Elareshi, University of Tripoli \\ Maha Alrashid, Bahrain University
}

\begin{abstract}
An online survey is reported that was carried out with more than 385 social media users aged 18 and over and extracted from nine Arab countries; Bahrain, Egypt, Algeria, Libya, Iraq, Kuwait, Syria, Jordan and Yemen. This research focuses on the use of Facebook by a selected group called Open Media Library (OML) which have interests in social media use. The aim of this research is to understand how and why users utilise Facebook and what their attitudes and perceptions are towards the purposes of Facebook. It examines how OML users utilise information and knowledge posted on Facebook, their preferred topics and motivations and the gratifications they obtained. Theoretical models of the purposes of Facebook usage in the literature were examined. As stated in the literature, this research confirms that Facebook can be used/defined as communication, collaboration and resource-sharing, as well as for intercultural communication and intercultural relationships. Curiosity and escapism, communication and experience, friendship and entertainment and identification of news and events are the main motivations for using Facebook. The findings are discussed in terms of their implications for the future of social media and its impacts on intercultural communication, media use and intercultural relationships.
\end{abstract}

Keywords: Facebook, social media, intercultural communication and relationships, culture, uses and gratifications, motivations, Arab youth. 


\section{Background}

The last 20 years have witnessed huge developments in technology information, especially after the spread of the Internet in the Arab world. New technologies linked to the Internet and smart phones have played a critical role as communication platforms that enable their individuals to communicate and share knowledge together. One of the most interesting applications used in the Arab world is Facebook (Arab Social Media Report, 2015). It has become a popular tool for communication between Arab people and an interesting subject for scientific research too. Academically, EBSCO has reported returning 634 articles on Facebook in the field of published psychology journals between 2014 and 2015. There is, however, a dearth of data on the relationship between social media use, mainly Facebook, and academic knowledge in the Arab world, on factors that influence Arab users' perspectives and on how this application has affected the way in which Arab users are communicating. In other words, there is a need for greater understanding of the effects of social media, such as Facebook, in the modern life of Arab users. In this regard, there has been some thought about what role the social "new" media are currently playing and what impact they will have on future social and educational developments in the Arab world (Błachnio, Przepiorka, Boruch, \& Bałakier, 2016).

Historically, in 1979, Tom Truscott and Jim Ellis created the Usenet, a worldwide discussion system that allowed users to post information. However, social media, as we now know, started in the late 1980s when Bruce and Susan Abelson founded Open Diary, an early system for social networking that brought together online daily writers into one community (Kaplan \& Haenlein, 2010). The growing ability of high Internet speed access further added to the popularity of social media, including Myspace (2003) and Facebook (2004). This has shaped the development of social media. The most recent addition to this glamorous grouping has been the virtual world or, as it was known, Lab's Second Life (Kaplan \& Haenlein, 2009). Terminologically, the rise in interactive digital media has catapulted online users from the old Web 1.0 to the highly interactive Web 2.0 world. Social media is a formal definition, known as Web 2.0 and User Generated Content (UGC). The term UGC was introduced in 2005 and used to describe the various forms of media content that are publicly available and created by end-users. UGC is also a term used to describe a new way in which software developers and users started to use the Internet, as a tool whereby content and applications are no longer created and published by individuals, but instead are continuously modified by 
all users (Android system or Google mission). Web 2.0 can be seen as a platform for the evolution of social media. UGC, on the other hand, can be seen as the sum of all ways in which online users utilize social media.

Facebook allows users to be formatted in specific/closed groups that have similar interests (Jung \& Sundar, 2016). These groups can create certain goals and specific targets. Facebook provides the users of the group an area of freedom where they can have more of a mini-forum dialogue. It also allows users the opportunity to coordinate between each other to organize meeting through what is known as "Events", to invite members of these groups to the meetings and to know who attended the meeting and who did not. There are many groups on Facebook designed to focus on studying different disciplines including media and communication. Arab media users have created several groups to reach others throughout the world. There are an estimated 50 Arab academic groups on Facebook, such as the Egyptian Media Library for Research (18,263 members), Open Media Library (OML) (11,884 members), Media Research and Studies (7,150 members) and Platform for Media Professors in the World (4,242 members).

Facebook has given users in the Arab world opportunities to speak out and communicate about issues of their choosing and to reach large numbers of others. For example, the OML Group (created and managed by Abdul-Karim Ziani, assistant professor at the University of Bahrain) has provided users with opportunities to obtain news and information regarding the media and academic field and, hence, to absorb different news regarding their own positions, locations and other matters. OML Group connects Arab media users and those who have similar interests in the field as well as allowing them to share opinions and keep up-to-date with their academic and media work and their friends' lives. OML Group has become a new way of replacing other forms of electronic communication such as emails and chat-rooms (Menaceur, 2015).

Further, there has been an increased academic focus on the growth and use of social media in the Arab world and this has adopted a variety of theoretical and methodological perspectives (Błachnio et al., 2016; Gunter, Elareshi, \& Al-Jaber, 2016). What is clear is that in social media, Facebook, Twitter, YouTube and other applications, use has become more widespread across the Arab world, not only as a toolkit for politics, but also as an important 
communications device for many ordinary people in their regular professional and private lives. In this context, there is a growing need to understand the long-term implications for Arab users. Such an explosion of social media and knowledge of the capabilities and advantages of networking, have brought to young Arab Facebook users not only entertainment, but also the use of social networks for educational purposes in a different and modern way. This paper is designed to shed new light on these matters.

\section{Literature Review}

The role played by digital media technologies in providing their users with different news and information in the Arab world is not a surprise. However, huge investment in online infrastructures has seen them advance more rapidly in some parts of the Arab world than anywhere else (United Nations, 2012). Digital technology tracking has revealed that the annual rate of internet penetration growth in the Arab world between 2006 and 2015 was 52.2 per cent, a total of $123,172,132$ of the population, with 49,400,000 Facebook subscribers (a 20.9 per cent penetration rate) (Arab Social Media Report, 2015; Cole, Suman, Schramm, Zhou, \& Tang, 2012).

When it comes to further statistics for Arab countries, where the present study was conducted, Facebook is by far the most popular social media in the region, as found by several recent studies, projects and research centers (Arab Social Media Report, 2015; Dennis, Martin, \& Wood, 2013; Gunter et al., 2016; Salem, Mourtade, \& Alshaer, 2014). Dennis at al. (2013) found that the majority (94\%) of social media users were active on the network, while more than half $(52 \%)$ of them used Twitter, followed by $46 \%$ using Google+, 14\% Instagram and only 6\% LinkedIn. Arabian Gazette (2015) found that Facebook was one of the most popular social-media networking tools in the Arab world, with two out of five users saying that Facebook was their favorite. Jordanian and Libyan users were top in preferring Facebook (63\% and 50\% respectively). A vast majority of Facebook users (89\%) said that they checked Facebook daily (Arabian Gazette, 2015). The largest Arab age groups were those in the early 20s and 30s brackets (www.socialbakers.com). These figures confirm the large impact of the Facebook phenomenon on society, the economy and business (Thompson, 2013; Thongmak, 2014). Several studies have investigated the use of Facebook before, but the novelty of this one lies in its investigation of Arab media and academia (OML 
Group) and in the need for understanding and exploring group users' attitudes, motivations and gratifications.

Studies have been conducted in order to analyze the use of social media for educational and learning purposes (Dabner, 2012; Donlan, 2014; Junco, 2015; Sharma, Joshi, \& Sharma, 2016). Some of these studies have found Facebook a useful tool for academic life and a way to help students to fulfil their daily activities such as going to lectures and performing tasks. Qureshi at al. (2014) state that using the numerous advantages of Facebook, students and professors can share many resources of both an entertaining and an educational character, materials and multimedia clips, as well as a great number of illustrations that can be of help in traditional ways of learning. Further, some studies, (e.g., Mazman \& Usluel, 2010; Sanchez, Cortijo, \& Javed, 2014), have investigated how users can utilize Facebook for educational purposes. These studies used structural equation modelling to explore relationships between adoption processes, user purposes and educational usage of Facebook. They found that there are three main constructs of Facebook educational usage: communication, such as communication among students and their professors, facilitating class discussion and providing information about resources and courses; collaboration which stands for activities such as users' joining academic groups (in our case, OML Group) and carrying on group works by sharing homework, projects and ideas; and sharing resources/materials, including activities such as exchanging multimedia resources, videos, audios, animated videos etc. (Mazman \& Usluel, 2010).

Theoretically, the background for this study is based on social-presence theory, socialprocesses perceptive (self-presentation) and motivation theory. These theories and perspectives are important in understanding such phenomena. In brief, we argue that socializing (those in the same field) and self-presentation are the main motives for using Facebook. Some studies have found that there are other motivations. For example, Brandtzæg et al. (2010) found that entertainment and leisure is one of the motives for using Facebook. Other motives, as identified by Ellison et al. (2007), included keeping up with others' lives or integrating with other users (university students).

To create a classification definition for social-media use, some theories and concepts in the field of media research were used, such as social-presence theory, social-processes perceptive 
(self-presentation) and motivation theory. Social-presence theory, according to Short, Williams and Christie (1976) indicates that "the degree of salience of the other person in the interaction and the consequent salience of interpersonal relationships". Media differ in the degree of social presence, defined as the acoustic, visual and physical contact that can be achieved. They allow merging between two communication partners. Short and his colleagues argue that the fewer the channel or codes offered by a medium, the less energy users devote to the existence of other social members and vice versa. In other words, the higher the social presence, the larger the social influence that communication partners have on each other's behavior. Social presence is influenced by interpersonal (e.g., face-to-face discussion or live chat) and asynchronous (e.g., e-mail) communication and can be expected to be lower for mediated.

According to Goffman (1959), in social processes or self-presentation, people engage in performances to leave a positive impression on others. In so doing, individuals may try to emphasize their positive attributes and conceal any negative ones, thereby editing their selfpresentation so as to be perceived in an acceptable manner. Self-presentation states that in any type of social interaction, individuals have the desire to control the impressions that other people form of them. This is maybe why people decide to create a personal online account/page to present themselves in cyberspace (Schau \& Gilly, 2003) and to do other things such as looking for news, information or knowledge. Through Facebook, Arab users have been enabled, perhaps for the first time, to access news and information and thousands of profiles of other applications users, including academic information and studies. This process is quite different from the traditional practice, in which information regarding the academic field is held in libraries and research centers. However, constructing their own online profiles in social media - e.g., Facebook - enables users not only to control information, but also to repost and to share knowledge more openly with those users who have similar attitudes. In this regard, as Walther (1996) indicates, due to its synchronicity, social media, especially Facebook, allow users to be quite strategic in reducing a potential user's access to undesirable attributes because they can form, manage and strategically modify their self-presentation consciously.

Another framework we used in this study was the uses and gratifications (U\&G) paradigm that has been prominent over many decades in allowing media scholars to conceptualize and 
investigate off and online users' motivations (Kayany \& Yelsma, 2000). As well as focusing on individual use and choice of media (Katz, 1959). Users' motives have not only been measured to try to predict broad media-use choices, but more usefully perhaps, to understand why people/users may turn to one medium/site over another.

The main purpose of this paradigm in this study is to explain the reasons that respondents choose a specific medium - e.g., Facebook - over another and to elucidate the psychological needs that motivate respondents to use Facebook. This paradigm assumes that users are goaldirected in their behavior and are aware of their needs. Purposive value, self-discovery, entertainment value, social enhancement and maintaining interpersonal connectivity are the key values (or needs) that are widely adopted to determine the use of virtual communities (online) (C. M. K Cheung \& Lee, 2009).

Functionally, social media sites (in our case, Facebook) are applications that enable their users to connect by creating personal-information profiles, inviting friends and colleagues to have access to those profiles and sending/receiving e-mails and instant messages between each other. These profiles can include any type of personal information such as photos, videos, audio files, blogs and short/long messages. In the Arab world, like elsewhere, social media are of very high popularity among young users (Arab Social Media Report, 2015; Bajnaid, 2016; Dennis, Martin, \& Wood, 2014; Salem et al., 2014).

Facebook now has over 1.55 billion users, with 800 million Facebook messenger users (The Statistics Portal, 2016). The total number of Facebook users increased by 13\% from 2014 to 2015 as reported by zephoria.com (2015). What is more, research conducted in 2011 in the US found that $90 \%$ of students used Facebook and only 37\% used Twitter (Dahlstrom, de Boor, Grunwald, \& Vockley, 2011). When it comes to the Arab world, according to Arab Social Media Report (2015) Facebook and WhatsApp are the most used social-media channels. Facebook is the most used social-media channel on the aggregate level of the Arab world. Youth represents the majority of social-media users with 67\% aged between 15 and 29 years old (Salem \& Mourtade, 2014). This clearly indicates the dominance of Facebook among young Arab people. 
Educational institutions, such as universities and colleges, have also focused on developing programs and activities for students that rely on social-media networking and the main factor affecting the formation of social networks is the need to connect a group of users, or "beneficiaries", who have the same cognitive concerns (Junco, 2015; Thongmak, 2014). Use of Facebook in the Arab world provides an important background for the social, emotional and knowledge needs of young Arab people who spend most of their time on the Internet (Arab Social Media Report, 2015). Arab Social Media Report (2014) indicates that there are more than 135 million individuals using the Internet across the Arab world. This is coupled with a mobile penetration rate of around 110 per cent on a regional level and more than 71 million active users of social-media sites. These figures are not surprising if we know that there are around 400 million mobile devices and millions of other Internet-connected devices used in the Arab world. This can be seen, on the other hand, as creating new opportunities and challenges for governments, businesses and societies on economic, social, educational and policy levels.

In this paper, we examined the nature of the use of Facebook by OML Group which places much of its focus on the use of Facebook for education and communication purposes. We also examined the motivations respondents give for using Facebook and their perceptions and opinions of the information they obtain. The research questions were therefore concerned with exploring and perceiving Facebook in terms of education and communication.

Q: What are the demographic characteristics of the OML Group and how does it use Facebook?

Q: How do OML users present themselves on Facebook?

Q: What are the perceptions of OML Group regarding the effectiveness of using Facebook?

Q: Does OML associate different gratifications with using Facebook?

\section{Method}

The main data set out in this paper was obtained from an online questionnaire administered using monkeysurvey.com. The questionnaire targeted the OML Group page. A random sample of Facebook users was drawn up with the aim of matching the research question. Based on a review of the literature, a set of statements concerning Facebook use, motivations, gratifications and behaviors was developed. The main aim of developing this questionnaire was to obtain an instrument for measuring different aspects of Facebook group use and the 
level of attachment to Facebook. Most of the questions were adopted from past studies bearing in mind the culture of the Arab world. The questionnaire comprised 18 questions and was divided into two main parts. The first set of questions was designed according to Likerttype items which represented measuring scales for assessing the purposes of Facebook usage and motivation. The level of respondents' agreement with individual scale items was measured using a five-point scale $(1=$ strongly disagree and $5=$ strongly agree $)$.

The last part was designed to collect data regarding users' demographic characteristics (gender, age, level of education, status and annual income), Facebook knowledge ("How do you know about Facebook?”), access (“Where do you access Facebook?”), time spent on Facebook ("How often do you use Facebook?"), frequency of social-media usage ("How often do you use social media?") and identification of topics followed ("What types of topics do you follow on Facebook?"). This paper will present findings for exploring OML Group uses, perceptions and motivations regarding Facebook. The requirement for participating in this study was membership of OML Group. Respondents were asked to state how they knew about Facebook, where they surfed it, the time they spent on Facebook, how often they used other social-media sites, the types of relationship they had on Facebook, whether they used real names or nicknames, the topics they followed on Facebook and their reasons and motives for using Facebook.

It should be noted that since the current study has an exploratory element and a new construct of Arab Facebook use will be tested here, only general assumptions were formulated in order to verify the possible directions for further studies examining Facebook behavior. Such an attempt aims at examining OML Group users' perceptions, experiences and attitudes regarding using Facebook for academic news and information.

\section{Results}

The results reported in this paper were drawn from a regional online survey administered by a group of academic staff, targeting users of the OML Group page. The survey fielding was conducted between June and September 2015 with respondents numbered at almost 374. Responses were received from all countries in the Arab region. The sample consisted primarily of OML Group usages as it was administered via an online survey. Out of 374 investigated users, $57.7 \%$ were female and $42.3 \%$ male, divided by age as follows: less than 
20 years old (6.9\%), 21-30 (59\%), 31-40 (21.9\%) and more than $41(12 \%)$. Their education was measured, with $4.3 \%$ of the sample being in high school, $35.6 \%$ at university, $11.6 \%$ having a diploma and $48.5 \%$ having reached $\mathrm{MA} / \mathrm{PhD}$ level. Regarding their status, $57.5 \%$ of the sample was single, $40.8 \%$ married and $1.7 \%$ divorced. The native countries were as follows: Bahrain (27.7\%), Egypt (17.6\%), Algeria (14.6\%), Libya (14\%), Iraq (83.5\%), Kuwait $(7.1 \%)$, Syria (6.6\%), Jordan $(2.2 \%)$ and Yemen $(0.5 \%)$. This paper reported the answers from a selected number of questions which were part of a larger survey.

\section{How Do You Know about Facebook?}

When it comes to how respondents got to know about Facebook, more than half $(53.8 \%)$ said they knew it from their colleagues and friends, with the rest replying as follows: family $(19 \%)$, the internet $(14.3 \%)$ and media $(10.9 \%)$. The chi-square test revealed one significant difference among demographic groups, with those having reached MA/PhD level (54\%) more likely than the others (university level $33.1 \%$, diploma $10.8 \%$ and high school $2.2 \%$ ) to say that they knew of Facebook via their colleagues or friends, $X^{2}=20.821, \mathrm{df}=12, \mathrm{p}<0.05$.

\section{Reported Places Where Users Access Facebook}

Until recently, internet users commonly used and accessed the Internet through their desktop computers or laptops. However, with the spread of mobile devices, the ways in which Arab users go online are varying. In this survey, Facebook users were asked in which location they used the Internet. The most common location was the home (81.6\%), followed by "everywhere" (9.9\%). But few respondents (less than 1.5\%) did so in public places, university cafés, workplaces and net cafés. These percentages show that respondents are more likely to connect to the Internet when at home than when they are in other places. These findings are consistent with of those found by some recent studies on Internet access, which indicate that around $88 \%$ of Arab online users access the Internet from home, 56\% from work and only $9 \%$ from school or university (Salem et al., 2014). There was one significant gender difference regarding places for surfing the Internet. Female respondents (60.3\%) were more likely than males $(39.7 \%)$ to surf the Internet at home, while male respondents $(80 \%)$ were more likely than females $(20 \%)$ to do so at universities, "everywhere" (55.6\% versus $44.4 \%$ respectively), at work ( $75 \%$ versus $25 \%)$, cafés ( $75 \%$ versus $25 \%)$, net cafés $(100 \%$ versus $0 \%) \mathrm{X}^{2}=13.486, \mathrm{df}=6, \mathrm{p}<0.05$. One explanation of different results is that Arab men are more likely to be outdoors during the day, while women are usually indoors. 


\section{Time Spent on Facebook per Day}

When it comes to the frequency of Facebook usage, 36.1\% of respondents spent less than one hour daily on Facebook, while $23.5 \%$ used it for more than 3 hours a day. Similar findings were found by Arab Social Media Report (2014). They found that 28\% of their respondents indicated spending 3-4 hours on the Internet. Manasijević at al. (2016) found that 48.7\% of Facebook users use Facebook 2 to 5 times daily. Those aged 21-30 (67.1\%) were more likely than the other groups, such as those aged less than 20 (17.8\%), those 41 and over (8.2\%) and those 31-40 (6.8\%) to spend less than one hour using Facebook, $X^{2}=32.509, \mathrm{df}=9, \mathrm{p}<0.000$. University student users $(71.2 \%)$ were more likely than the other groups to spend less than one-hour browsing Facebook (15.1\% MA/PhD level, 9.6\% high school and 4.1\% diploma), while MA/PhD respondents $(48.9 \%)$ were more likely than those at university $(29.8 \%)$, those with diplomas (19.1\%) and those at high-school level (2.1\%) to spend 1 to 2 hours browsing Facebook, $X^{2}=80.765, \mathrm{df}=9, \mathrm{p}<0.000$. These findings are consistent with Manasijević at al. (2016) who found that Serbian users spent a daily average of 2.76 hours on Facebook. Thompson (2013) indicates that students today spend most of their time on social media.

\section{Reported Used of Different Social-media Sites}

The most popular daily activities that respondents do when they are on social-media sites is use Facebook (60.3\%), followed by Instagram (40\%), YouTube (32.1\%) and Google+ (20\%). This finding was not surprising as Facebook was found to be the most popular social network in the Arab world, followed by Google+, YouTube and Twitter (Arab Social Media Report, 2015; Dennis et al., 2013; Salem et al., 2014). There were a number of significant differences regarding the use of different social-media websites. Such differences emerged for Facebook, Twitter and YouTube. Those aged 21-30 (55\%) were more likely than the other groups (those aged $31-40(29 \%), 41$ and over (15\%), less than 20yrs $(1.3 \%)$ ) to use Facebook, $\mathrm{X}^{2}=40.633$, $\mathrm{df}=6, \mathrm{p}<0.000$. Those aged 21-30 (67\%) were also more likely than the others (those aged less than $20(22.2 \%), 31-40(11.1 \%), 41$ and over $(0.0 \%))$ to use Twitter, $X^{2}=21.254$, $d f=9$, $\mathrm{p}<=0.012$. Those aged 21-30 (67\%) were more likely than the others (31-40 (16.4\%), less than $20(14 \%) 41$ and over $(4.1 \%))$ to use YouTube, $X^{2}=26.354, \mathrm{df}=9, \mathrm{p}=0.002$. There was also a significant education-level difference in using Twitter, with $\mathrm{MA} / \mathrm{PhD}$ respondents $(66 \%)$ being more likely to use Twitter than others (university (19.4\%), diploma (14\%) and high school $(1.3 \%)), \mathrm{X}^{2}=82.558, \mathrm{df}=6, \mathrm{p}=0.000$. Education level was also found to be significant among the respondents, with university respondents $(52.1 \%)$ being more likely 
than others to use YouTube (MA/PhD students (36\%), diploma (7\%) and high school (6\%)), $X^{2}=31.105, \mathrm{df}=9, \mathrm{p}=0.000$.

\section{Real Name vs. Nickname}

One of the purposes of this paper was to check whether respondents use their real name or a nickname in communicating with others. The majority of respondents $(82 \%)$ indicated that they used their real names to communicate, while few (18\%) did not do so. When the chisquare test was run, several significant differences emerged. As expected, female respondents $(81.4 \%)$ were more likely than males $(18.6 \%)$ to use nicknames on their Facebook page, $\mathrm{X}^{2}=16.379, \mathrm{df}=1, \mathrm{p}=0.000$. Arab women are expected to use nicknames, rather than their real names, for traditional cultural reasons. For example, Aljasir (2015) indicates that in light of Arab Islamic culture (in Saudi Arabia, for example), social norms encourage men to be proud of their names and heritage, while this is considered inappropriate for women. Those aged 21-30 (55.2\%) were more likely than those aged 31-40 (24.2\%), 41 and over (13\%) and less than $20(7.7 \%)$ to use real names on their Facebook page, $X^{2}=7.614, \mathrm{df}=3, \mathrm{p}=0.055$.

Furthermore, respondents were asked about their Facebook profiles and how they identified themselves on Facebook. Nearly half of the respondents $(46.3 \%)$ used their own photos, while (31.8\%) used other people's photos. Only $17 \%$ used expressive names in their profiles and $4.9 \%$ used no photos. Male respondents $(67.3 \%)$ were more likely than females $(33 \%)$ to use their own photos, while females $(86 \%)$ were more likely than males $(14 \%)$ to use other people's photos. Females (69\%) were also more likely than males $(31 \%)$ to use no photos at all and to use expressive names ( $69 \%$ vs. $31 \%$ respectively), $X^{2}=77.025, d f=3, p=0.000$. These findings are consistent with Aljasir (2015) and Moaddel (2013) who found that men are more likely than women to use their real photos in their profiles. Those aged 21-30 (51\%) were more likely than those aged 31-40 (28\%), those 41 and over (17\%) and those less than $20(5 \%)$ to use their own photos on their Facebook page, $X^{2}=25.330, d f=9, p=0.003$. $\mathrm{MA} / \mathrm{PhD}$ respondents (56\%) were more likely than the others to use their own photos (university respondents $30.3 \%$, diploma $10 \%$ and high-school level 5\%), $X^{2}=23.957$, df=9, $\mathrm{p}=0.004$. 


\section{Topics Most Followed on Facebook}

Respondents were asked to evaluate a list of 15 topics in terms of their perceived importance on the form. Topics were selected to cover a wide range of areas or programs and it was essential to explore which respondents were more or less likely to see certain topics as legitimate types of program. The majority of respondents indicated that the type of topics they followed were social topics $(71.2 \%)$, cultural $(64.6 \%)$, scientific $(61.3 \%)$, politics (48.9\%), religion (46.4\%), arts (36.5\%), science and technology (36.3\%), women $(27.5 \%)$, services $(26.1 \%)$, sports $(21.2 \%)$ and children $(20.1 \%)$.

\section{Purpose of Using Facebook}

Further analyses were performed to examine the reasons for using Facebook. A total of $72.5 \%$ of investigated respondents stated that the most important purpose for using Facebook was to communicate with colleagues and friends, while few respondents (6.4\%) used Facebook for research and study purposes, for communicating with universities and other organizations (4.5\%) and for communicating with the opposite gender (1.9\%). These findings are consistent with others who found that most Arab online users, and those elsewhere, use social media to stay in touch with friends and family, to get news and information on various issues, for professional uses, for job hunting, for searching and sharing opinions or for political activities (Ellison, Steinfield, \& Lampe, 2011; Manasijević et al., 2016; Reuben, 2008; Wong, Kwan, Leung, \& Wang, 2014). Those aged 21-30 (62.3\%) were more likely than the other groups (those aged 31-40 19.1\%, 41 and over 10.2\% and less than $208.3 \%$ ) to use Facebook to communicate with colleagues and friends, $X^{2}=22.677, \mathrm{df}=12, \mathrm{p}=0.031$. $\mathrm{MA} / \mathrm{PhD}$ respondents $(45 \%)$ were more likely than the other groups to communicate with colleagues and friends via Facebook (university 40\%, diploma 11\% and high-school level $5.1 \%), X^{2}=33.586, d f=12, p=0.001$. In this regard, research has shown that between $67 \%$ and $75 \%$ of college students use social-media sites (Junco, 2015). Statue was also tested here and found that single respondents $(60.5 \%)$ were more likely to communicate with colleagues and friends via Facebook than were others (married 40\%, divorced $0.0 \%$ ), $\mathrm{X}^{2}=38.480$, df=8, $\mathrm{p}=0.000$.

\section{Motivations for Using Facebook}

Respondents who indicated that they used Facebook daily or quite often were asked to clarify their motivations for using Facebook and also to indicate the gratifications derived from it. 
There were 21 motivated statements associated with using Facebook. When analyzing the motivations, the scores were as follows: "to communicate with family and friends" $(90.7 \%)$, "to gain new experience and information beneficial to me" (88.5\%), "to exchange views with others via discussion" (86.6\%), "to obtain information about the world I'm living in" (85.6\%), "to communicate with people I cannot communicate with directly" (83.8\%), "to share photos, themes and passages with others2 (72.4\%), "to post my personal activities2 (71.1\%), "for entertainment" (68.7\%), "to identify events and news fashions" (65\%), "to get rid of boredom and fill leisure time" (64.6\%), "to discover the world of social media" (63.9\%), "it is pleasant to use" $(60.5 \%)$, "to identify new goods and services in markets" (58.8\%), "part of the routine I do when I'm online" (55.2\%), "to make friends of those who have not found me" (43.9\%), "because of curiosity" (42\%), "to forget about worries away from my family and friends" (35.5\%), "so I don't feel lonely and alienated" (32.5\%), “to escape from everyday life problems" (31.8\%), "because all around me use it" (31\%), "I use it when I'm frustrated"' $22.8 \%)$.

Factor analysis through the principal component analysis with varimax rotation was applied to the 21 general motivations to derive a smaller number of factor variables for subsequent multivariate data analysis. In doing so, the factoring criteria were: a factor Eigenvalue $\leq 1$, a minimum primary loading $\leq .40$ on factor and each item has a loading of $\leq .40$. Further statistics were applied, for example, the reliability of the measurement was tested by using a common reliability test of Cronbach's alpha (.896). Further tests were run using Bartlett's test of sphericity [(2322.040) $(P<.000)]$, followed by the KMO value, which was $.874(P<.000)$, which signaled that the data were suitable for factor analysis. In this analysis, four factors with Eigenvalues greater than one emerged, explaining the $58.01 \%$ of the total variance. Table 1 below shows the results of the factor analysis along with means of the motivation, variances and the reliability analysis performed for all the factors and their values.

Table 1 Factor analysis of motivations for using Facebook

\begin{tabular}{|c|c|c|c|c|}
\hline & \multicolumn{4}{|l|}{ Factors } \\
\hline & $\begin{array}{ll}\mathbf{M} \quad 1 \\
\end{array}$ & 2 & 3 & 4 \\
\hline F1: Curiosity and Escaping & 3.21 & & & \\
\hline Because of curiosity & $2.97 \quad .525$ & & & \\
\hline To escape from everyday life problems & $3.26 \quad .818$ & & & \\
\hline
\end{tabular}




\begin{tabular}{|c|c|c|c|c|c|}
\hline So I don't feel lonely and alienation & 3.29 & .850 & & & \\
\hline Because all around me use it & 3.31 & .653 & & & \\
\hline I use it when I'm frustrated & 3.59 & .771 & & & \\
\hline As part of routine I do when I'm online & 2.79 & .615 & & & \\
\hline Forgetting about the worries away from my family and friends & 3.26 & .719 & & & \\
\hline F2: Communication and Experience & 2.01 & & & & \\
\hline To communicate with family \& friends & 1.68 & & .623 & & \\
\hline To gain new experiences \& info beneficial to me & 1.73 & & .689 & & \\
\hline To post my personal activities & 2.31 & & .606 & & \\
\hline To share photos, themes and passages with others & 2.24 & & .626 & & \\
\hline To obtain information about the world I'm living in & 1.82 & & .700 & & \\
\hline To exchange views with others via discussion & 1.85 & & .734 & & \\
\hline To communicate with people I cannot communicate with them directly & 1.89 & & .640 & & \\
\hline It is pleasant to use & 2.56 & & .440 & & \\
\hline F3: Friendship and Entertainment & 2.57 & & & & \\
\hline To make friends of those who have not found around me & 2.92 & & & .571 & \\
\hline For entertainment & 2.35 & & & .805 & \\
\hline To get rid of the boredom \& fill leisure time & 2.43 & & & .734 & \\
\hline F4: Identification of News and Events & 2.47 & & & & \\
\hline To identify events \& news fashions & 2.48 & & & & .733 \\
\hline To identifying new goods \& services in markets & 2.54 & & & & .773 \\
\hline To discover the world of social media & 2.39 & & & & .412 \\
\hline Eigenvalues & & 6.91 & 2.67 & 1.36 & 1.23 \\
\hline$\%$ Variance & & 32.94 & 12.71 & 6.48 & 5.87 \\
\hline Cronbach's alpha (reliability score \%) & & .87 & .84 & .74 & .68 \\
\hline
\end{tabular}

Extraction Method: Principal Component Analysis. Rotation Method: Varimax with Kaiser (Eigenvalue > 1). Higher mean scores indicate high agreement, while lower scores indicate less agreement. Items measured on a 5 -point scale ( $1=$ strong disagree and $5=$ strong agree). The four factors solutions were: F1, called Curiosity and Escaping. Seven motivated items dealing with this factor were loaded. The mean scale of these seven items was $(\mathrm{M}=3.21$, on a 5-point scale). F2, called Communication and Experience, was defined by eight items $(\mathrm{M}=2.01)$. F3, called Friendship and Entertainment, was defined by three items $(\mathrm{M}=2.57)$. F4, called Identification of News and Events, was also expressed by three items $(\mathrm{M}=2.47)$. These outputs offered a very orderly solution that confirmed correlation coefficients between these variables. Respondents can be clearly clustered into those who were mostly motivated 
to use Facebook for the above reasons. The interrelationships between the different F1 and F2 factors were particularly strong, as evidenced by their Eigenvalue scores. However, the interrelationships among F3 and F4 were not quite as strong, as shown by their lower Eigenvalue scores. The factor-analysis outputs reveal that even among respondents (Facebook users), there are distinct motivation segments in the population, defined by their agreed motivations. Further, respondents who fell into different demographic groups displayed different motivations for using Facebook. The significant levels are shown based on the Mann-Whitney U test and the Kruskal-Wallis H test. There were no marked gender differences in the motivated items, apart from two exceptions. One was "posting my personal activities", with female respondents $(58.3 \%)$ being more likely than males $(40.7 \%)$ to indicate this motivation as highest agreement, $U(318)=10703.500$; exact $P<.05$, 2-tailed. However, male respondents $(62.3 \%)$ were more likely than females $(37.7 \%)$ to indicate that they "make friends of those who have not found them", $U(310)=9543.500$; exact $P<.005$, 2tailed. These results are consistent with those found by Gourdeau (2015) and others who found that Facebook application may be more attractive to females than to males and that females are more active on Facebook than are males.

\section{Discussion}

The aim of this study was to explore different patterns of Facebook usage and the motivations associated with users' perceptions and opinions. The outcomes of the study revealed several interesting findings. It is clear that developments in the use of online social media in the Arab world form part of a wide sphere of technological revolution spanning the whole Arab world. This was started by the growth in the use of online media, e.g., reading, listening and watching different media online, in addition to the ability of people to use e-mails and chatrooms, and these technologies quickly became adopted as tools of everyday life, including political activities, especially with the greater ability to buy and use smart phones via broadband and WiFi connections (Ziani \& Elareshi, 2016). The latter was more noticeable around mid-2000. It has also been noted that the online world can be used and produced by anyone who has basic computer and Internet skills. In other words, to be an active user does not require much knowledge. Interestingly, in this world, some users attract more followers and online friends than do others (Lawrence, Sides, \& Farrell, 2010; Wu, Hofman, Mason, \& Watts, 2011). This is true regardless of whether the users are specialists in certain fields or whether they write about celebrity, politics, education, fashion and lifestyle issues. Some 
users can achieve an almost celebrity-like status if they command the regular attention of millions of followers (Gunter, 2014; Hindman, 2010).

It is quite interesting to note that social media in the Arab world is perceived as having numerous positive aspects that enhance the quality of life of people, as well as enhancing business profitability, the education system and governmental interactions with the public. Regarding social-media perceptions, however, Arab users have shown a lack of trust in the credibility of social-media content, with some users indicating that social media has some negative effects on local cultures and traditions, as cited by Arab Social Media Report (2015). For example, $81 \%$ of surveyed users said social media had made it easier for Arab people to connect with each other. The results of this study confirm such findings. Most respondents knew about Facebook via colleagues and friends and actually used Facebook to communicate with them. These social-media sites give everyone a place to share their personal stories and activities with their virtual friends and followers (Christy M.K Cheung, Chiu, \& Lee, 2011). In addition, this study confirms that the growth of social media in the Arab world is not limited to teenagers or members of the younger generation, with even those aged 40 and over (professors) increasingly using social media for different purposes. It is therefore reasonable to indicate that social media can be seen as a revolutionary new platform or trend. For example, although respondents indicated that they used Facebook daily in their lives, they did spend time on other social-media networks such as Instagram or YouTube. This result is consistent with Manasijević at al. (2016) and Thompson (2013) who found that users use Facebook 2 to 5 times daily, especially university students. Social media connect people with others who work, study and live around them (Christy M.K Cheung et al., 2011).

It appears that Facebook and other social networks (Instagram, YouTube) are highly used among respondents and there is a chance that these platforms can be used for communicating and sharing knowledge (Balakrishnan \& Shamim, 2013; Kaya \& Bicen, 2016). Surprisingly, few gender differences emerged with regard to self-disclosure. Such a finding indicates that Facebook allows its users to use the platform in ways that lessen or eliminate gender differences. Furthermore, the way in which respondents present themselves on Facebook varies. Most use their real names to communicate with others, while some do not. In most Arab conservative cultures, surprisingly, female users are more likely than males to use their real names. Most respondents also use their own photos in their profiles, with male 
respondents being more likely than females to do so.

It is clear that interactive digital-media platforms are changing the way in which people communicate and that the nature and sources of information and connectivity are vast. The results of this study point out a number of important implications for understanding why and how respondents use Facebook. Our analysis reveals four motivations for respondents to use Facebook: curiosity and escaping, communication and experience, friendship and entertainment and identification of news and events. This result is consistent with previous virtual community research. With online social networking sites, social interaction and connection are the objectives. They help people to learn more about events, parties and other social functions (Christy M.K Cheung et al., 2011). These findings support the assumption that media compete with other media platforms for selection, attention and use. This means that Facebook users may fulfil their friends' needs for attention and appreciation. Similar findings are cited by Aljasir (2015). Regarding the purposes for using Facebook, this study found that users use Facebook as a communication tool to communicate with friends and family members. They use Facebook for gaining new experience and beneficial information, for exchanging views with others, for entertainment, for sharing different things and for following specific friends who have similar interests. These findings are consistent with several studies such as Alemdar and Köker (2013) and Alhabash, Park, Kononova, Chiang and Wise (2012).

\section{Conclusion}

Social media, such as Facebook and Twitter, have been used differently in the Arab world. This is dependent on whether users are able to get access to the Internet, on their efforts and their locations. The more stable parts of the Arab world, for example, such as the GCC, have closely observed the changes taking place in less stable regions and the mediating role that digital-communications technologies have played. There is, therefore, a need for a deeper understanding of the power of social media and the use of this platform. This understanding must not grow out of prejudice or from anecdotal experience alone. It is best based on systematic and objective empirical inquiry and evidence. The status of such evidence, and the establishment of an effective research agenda for the future are desperately needed. It is the aim of this paper to facilitate this process. 
As a consequence, many groups on Facebook, ranging from open to closed groups, such as the academic field of media, are composed of individuals who have convergent interests and complementary roles within these communities. Creating such groups on Facebook allows the possibility to communicate with others who share interests or certain disciplines, to share files, photos and videos and to hold immediate talks. Given Arab Facebook users' mass adoption of social media and the evidence showing that it has become an integral part of their daily lives, it can be concluded that in line with previous studies, our respondents use Facebook for communications with friends and family. However, Facebook has also offered them a virtual space within which they can overcome the cultural barriers of society and this is especially so for women. Facebook enables its users to engage in activities through discussing, documenting and sharing personal views. 


\section{References}

Alemdar, M. ., \& Köker, N. . (2013). Facebook uses and gratıficatıons: A study directed to determining the Facebook usage of generations $\mathrm{X}$ and $\mathrm{Y}$ in Turkey. Mediterranean Journal of Social Sciences, 4(11), 238-249.

Alhabash, S., Park, H., Kononova, A., Chiang, Y. H., \& Wise, K. (2012). Exploring the motivations of Facebook use in Taiwan'. Cyberpsychology, Behavior, and Social Networking, 15(6), 304-311.

Aljasir, S. A. (2015). An investigation of Facebook usage by university students in Saudi Arabia. Coventry University, UK.

Arab Social Media Report. (2015). Arab Social Media Report 2015. Retrieved March 14, 2016, from

file:///C:/Users/p12003338/Documents/Downloads/ArabSocialMediaReport-2015 (1).pdf

Arabian Gazette. (2015). Social media in the Arab world. Retrieved March 15, 2016, from http://www.arabiangazette.com/social-media-in-the-arab-world-2015-report/

Bajnaid, A. N. (2016). A study of online impression formation, mate preferences and courtship scripts among saudi users of Matrimonial websites. University of Leicester.

Balakrishnan, V., \& Shamim, A. (2013). Malaysian Facebookers: Motives and addictive behaviours unraveled. Computers in Human Behavior, 29(4), 1342-1349.

Błachnio, A., Przepiorka, A., Boruch, W., \& Bałakier, E. (2016). Self-presentation styles, privacy, and loneliness as predictors of Facebook use in young people. Personality and Individual Differences, 94, 26-31. http://doi.org/10.1016/j.paid.2015.12.051

Brandtzæg, P. B., Lüders, M., \& Skjetne, J. H. (2010). Too many facebook "Friends"? Content Sharing and Sociability Versus the Need for Privacy in Social Network Sites. International Journal of Human-Computer Interaction, 26, 1006-1030. http://doi.org/http://dx.doi.org/10.1080/10447318.2010.516719

Cheung, C. M. ., Chiu, P.-Y., \& Lee, M. K. . (2011). Online social networks: Why do students use facebook? Computers in Human Behavior, (27), 1337-1343.

Cheung, C. M. K., \& Lee, M. K. O. (2009). Understanding the sustainability of a virtual community: Model development and empirical test. Journal of Information Science, 35(3), 279-298.

Cole, J., Suman, M., Schramm, P., Zhou, L., \& Tang, A. (2012). World internet project: International report. Retrieved March 16, 2015, from www.digitalcenter.org/wp- 
content/uploads/2013/01/2012wip_report4th_ed

Dabner, N. (2012). "Breaking Ground" in the use of social media: A case study of a university earthquake response to inform educational design with Facebook. Internet and Higher Education, 15(1), 69-78.

Dahlstrom, E., de Boor, T., Grunwald, P., \& Vockley, M. (2011). ECAR: National study of undergraduate students and information technology. Retrieved March 14, 2016, from https://net.educause.edu/ir/library/pdf/ERS1103/ERS1103W.pdf.

Dennis, E., Martin, J., \& Wood, R. (2013). Media use in the Middle East: An eight-nation survey. Retrieved from http://menamediasurvey.northwestern.edu/

Dennis, E., Martin, J., \& Wood, R. (2014). Entertainment media use in the Middle East: A six-nation survey. Retrieved from http://mideastmedia.org/

Donlan, L. (2014). Exploring the views of students on the use of Facebook in university teaching and learning. Journal of Further and Higher Education, 38(4), 572-588.

Ellison, N. B., Steinfield, C., \& Lampe, C. (2007). The benefits of Facebook "friends": Social capital and college students' use of online social network sites. Journal of ComputerMediated Communication, 12(4), 1143-1168. http://doi.org/10.1111/j.10836101.2007.00367.x

Ellison, N. B., Steinfield, C., \& Lampe, C. (2011). Connection strategies: social capital implications of Facebook-enabled communication practices. New Media \& Society, 13(6), 873-892.

Goffman, E. (1959). The presentation of self in everyday life. New York, NY: Doubleday Anchor Books.

Gourdeau, J. (2015). What men and women are doing on Facebook. Retrieved March 20, 2016, from http://www.forbes.com/2010/04/26/popular-social-networkingsites-forbeswoman-time-facebook-twitter

Gunter, B. (2014). Celebrity capital: Assessing the value of fame. London, UK: Bloomsbury Academic.

Gunter, B., Elareshi, M., \& Al-Jaber, K. (2016). Social media in the Arab world: Communication and public opinion in the Gulf states. London, UK: I.B Tauris Publishers.

Hindman, M. (2010). The myth of digital democracy. Ptinceton, NY: Princeton University Press.

Junco, R. (2015). Student class standing, Facebook use, and academic performance. Journal 
of Applied Developmental Psychology, (36), 18-29.

Jung, E. H., \& Sundar, S. S. (2016). Senior citizens on Facebook: How do they interact and why? Computers in Human Behavior, 61, 27-35. http://doi.org/10.1016/j.chb.2016.02.080

Kaplan, A. M., \& Haenlein, M. (2009). The fairyland of Second Life: Virtual social worlds and how to use them. Business Horizons, 52(6), 563-572.

Kaplan, A. M., \& Haenlein, M. (2010). Users of the world, unite! The challenges and opportunities of Social Media. Business Horizons, 53(1), 59-68. http://doi.org/10.1016/j.bushor.2009.09.003

Katz, E. (1959). Mass communication research and the study of popular culture: An editorial note on a possible future for this journal. Studies in Public Communication, 2(1), 1-6.

Kaya, T., \& Bicen, H. (2016). The effects of social media on students' behaviors; Facebook as a case study. Computers in Human Behavior, 59, 374-379. http://doi.org/10.1016/j.chb.2016.02.036

Kayany, J., \& Yelsma, P. (2000). Displacement effects of online media in the socio-technical contexts of households. Journal of Broadcasting \& Electronic Media, 44(2), 215-229.

Lawrence, E., Sides, J., \& Farrell, H. (2010). Self-segregation or deliberation? Blog readership, participation, and polarization in American politics. Perspectives on Politics, 8(1), 141-157.

Manasijević, D., Živković, D., Arsić, S., \& Milošević, I. (2016). Exploring students’ purposes of usage and educational usage of Facebook. Computers in Human Behavior, (60), $441-450$.

Mazman, S. G., \& Usluel, Y. K. (2010). Modeling educational use of Facebook. Computers \& Education, 55(2), 444-453.

Menaceur, K. (2015). Social media network as academic tool: A study of media group in the Facebook page. Journal of Social Studies and Research. University of Martyr Himmat Llikhadr, (13/14), 279-288. Retrieved from file://C:/Users/p12003338/Documents/Downloads/4131395

Moaddel, M. (2013). The birthplace of the Arab Spring: values and perceptions of Tunisians and a comparative assessment of Egyptian, Iraqi, Lebanese, Pakistani, Saudi, Tunisian, and Turkish publics. University of Maryland, MD.

Qureshi, I. A., Raza, H., \& Whitty, M. (2014). Facebook as e-learning tool for higher education institutes. Knowledge Management and E-Learning, 6(4), 440-448. 
Reuben, R. (2008). The use of social media in higher education for marketing and communications: A guide for professionals in higher education. Retrieved March 13, 2016, from http://doteduguru.com/wp-content/uploads/2008/08/social-media-inhighereducation.pdf

Salem, F., \& Mourtade, R. (2014). Citizen engagement and public services in the Arab World: The potential of social media. Retrieved February 16, 2015, from http://www.mbrsg.ae/getattachment/e9ea2ac8-13dd-4cd7-9104b8f1f405cab3/Citizen-Engagement-and-Public-Services-in-the-Arab.aspx

Salem, F., Mourtade, R., \& Alshaer, S. (2014). The Arab world online 2014: Trends in the internet. Retrieved March 19, 2015, from http://www.mbrsg.ae/getattachment/ff70c2c5-0fce-405d-b23f-93c198d4ca44/TheArab-World-Online-2014-Trends-in-Internet-and.aspx

Sanchez, R. A., Cortijo, V., \& Javed, U. (2014). Students' perceptions of Facebook for academic purposes. Computers \& Education, 70(1), 138-149.

Schau, H. J., \& Gilly, M. C. (2003). We are what we post? Selfpresentation in personal web space. Journal of Consumer Research, 30(3), 385-404.

Sharma, S. K., Joshi, A., \& Sharma, H. (2016). A multi-analytical approach to predict the Facebook usage in higher education. Computers in Human Behaviour, (55), 340-353.

Short, J., Williams, E., \& Christie, B. (1976). Theoretical approaches to differences between media. In The social psychology of telecommunication (pp. 61-76). London, New York: Wiley.

The Statistics Portal. (2016). Leading social networks worldwide as of January 2016, ranked by number of active users (in millions). Retrieved March 13, 2016, from http://www.statista.com/statistics/272014/global-social-networks-ranked-by-numberof-users/

Thompson, P. (2013). The digital natives as learners: technology use patterns and approaches to learning. Computers \& Education, 65(1), 12-33.

Thongmak, M. (2014). Factors determining learners' acceptance of Facebook in a higher education classroom. Knowledge Management and E-Learning, 6(3), 316-331.

United Nations. (2012). E-government survey 2012: E-government for the people. Retrieved March 12, 2015, from www.unpan1.un.org/intradoc/groups/public/documents/un/unpan048065

Walther, J. B. (1996). Computer-mediated communication impersonal, interpersonal, and 
hyperpersonal interaction. Communication Research, 23(11), 3-43.

Wong, K., Kwan, R., Leung, K., \& Wang, F. L. (2014). Facebook's potential for personal, social, academic and career development for higher education students. International Journal of Innovation and Learning, 16(2), 203-220.

Wu, S., Hofman, J. M., Mason, W. A., \& Watts, D. J. (2011). Who says what to whom on Twitter. In Paper present at the 20th International Conference on World Wide Web (pp. 705-714). New York, NY: ACM.

Zephoria.com. (2015). The top 20 valuable Facebook statistics. Retrieved March 20, 2016, from https://zephoria.com/top-15-valuable-facebook-statistics/

Ziani, A.-K., \& Elareshi, M. (2016). Mobile phone and Internet usage in the GCC region: University students' perspectives. In B. Gunter, M. Elareshi, \& K. Al-Jaber (Eds.), Social media in the Arab world: Communication and public opinion in the Gulf States (pp. 91-115). London and New York: I.B Tauris Publishers. 